\title{
TRỞ LỬC TỪ MỘT SỐ CHỦ THỂ TRONG HỆ THỐNG QUỐC TẾ TRÊN CON ĐƯỜNG TRỞ THÀNH BÁ QUYỀN CỦA TRUNG QUỐC
}

\author{
Nguyễn Ngọc Anh*
}

Trung tâm Nghiên cứu Giáo dục Ngoại ngũu, Ngôn ngũ và Quốc tế học, Truờng Đại học Ngoại ngũu, ĐHQGHN, Phạm Văn Đồng, Cầu Giấy, Hà Nội, Việt Nam

Nhận bài ngày 29 tháng 08 năm 2017

Chỉnh sửa ngày 15 tháng 09 năm 2017; Chấp nhận đăng ngày 28 tháng 09 năm 2017

Tóm tắt: Nghiên cứu trước tiên đề cập đến các nhận định về tham vọng quyền lực của Trung Quốc, tiếp theo đó là phân tích các trở lực đối với Trung Quốc đến từ các chủ thể trong hệ thống quốc tế gồm thể chế, định chế quốc tế, các quốc gia láng giềng và Hoa Kỳ. Nghiên cứu này cho rằng đây là các trở lực không dễ vượt qua vì vẫn còn một chặng đường dài phía trước để Trung Quốc có thể đạt được một quyền lực kết hợp giữa cứng và mềm vượt trội nhằm áp đảo và thuyết phục các chủ thể của các trở lực này.

Tù khoá: Trung Quốc, bá quyền, hệ thống quốc tế, quyền lực

\section{Đặt vấn đề}

Sau mấy thập kỷ kinh tế tăng trưởng cao, năm 2010, Trung Quốc đã trở thành nền kinh tế lớn thứ hai thế giới. Được hậu thuẫn bởi tiềm lực kinh tế dồi dào, Trung Quốc đã thực thi các chính sách đối ngoại nhằm nâng cao địa vị và ảnh hưởng của mình trong hệ thống quốc tế, trong đó đáng kể nhất là Sáng kiến Một vành đai-Một con đường (OBOR), Ngân hàng Đầu tu Cơ sở ha tầng châu Á (AIIB), cùng với đó là sự quyết đoán và cứng rắn trong các sự vụ quốc tế (Michael D. Swaire, 2010) và ngân sách quốc phòng hàng năm tăng hai con số(1). Người ta đã dùng cụm từ quyền lục đang chuyển dịch tì̀ Tây sang Đông để ám chỉ sự trỗi dậy và gia tăng quyền lực của Trung Quốc (Gideon Rachman, 2017). Giới nghiên cứu quốc tế cho rằng Trung Quốc đang muốn trở thành bá quyền. Bước sang thế kỷ 21, cả thế giới đã chứng kiến sự tăng tốc của toàn

\footnotetext{
*ĐT.: 84-912093346

Email: ngocanh2us@vnu.edu.vn

1 Thống kê của Viện nghiên cứu Hòa bình quốc tế Stockholm, truy cập tại: https://www.sipri.org/ databases/milex
}

cầu hóa và hội nhập quốc tế cũng như sự ràng buộc và phụ thuộc lẫn nhau giữa các chủ thể trong hệ thống quốc tế. Vì thế, trên con đường trở thành bá quyền, Trung Quốc sẽ gặp phải những trở lực nào và có vượt qua được hay không là vấn đề đang được giới học giả quốc tế quan tâm nghiên cứu. Nghiên cứu này cũng nằm trong $\mathrm{xu}$ thế đó. Tuy nhiên, giới hạn trong khuôn khổ một bài viết, nghiên cứu này chỉ xem xét trở lực đến từ các chủ thể của hệ thống quốc tế gồm thể chế, định chế và một bộ phận quốc gia dựa trên giả định Trung Quốc muốn trở thành bá quyền.

\section{Trung Quốc và hệ thống quốc tế}

Các nhà Hiện thực cấu trúc cho rằng hệ thống quốc tế là vô chính phủ, "có rất ít sự tin tưởng giữa các quốc gia. Các quốc gia lo sợ về những ý đồ của các quốc gia khác vì hầu hết những ý đồ này là rất khó đoán định. Nỗi sợ lớn nhất đối với một quốc gia là quốc gia khác có năng lực và động cơ để tấn công mình" (John J. Mearsheimer, 2013). Từ đó dẫn đến quan điểm sự phân bổ quyền lực tương đối giữa các quốc gia trong hệ thống quốc tế là 
yếu tố then chốt đối với an ninh và vị thế của mỗi quốc gia. Vì lý do này các quốc gia luôn không ngừng tìm cách tăng cường quyền lực, vì càng có nhiều quyền lực thì vị thế và an ninh của quốc gia đó trong hệ thống quốc tế càng cao và càng được đảm bảo. Chủ nghĩa Hiện thực cấu trúc còn cho rằng để đảm bảo an ninh cho mình, các quốc gia cần tìm kiếm càng nhiều quyền lực càng tốt, tốt nhất là có quyền lực áp đảo tất cả các quốc gia khác trong hệ thống quốc tế, tức là bá quyền. Việc tăng cường quyền lực cho mình để thu hẹp khoảng cách quyền lực với đối thủ chính là cách giảm thiểu sự đe dọa từ đối thủ.

Nhìn lại lịch sử, an ninh luôn là vấn đề quan tâm hàng đầu của Trung Quốc. Để đảm bảo an ninh quốc gia, ngay từ triều đại đầu tiên trong lịch sử Trung Quốc là nhà Hạ (Tk 2116 Tr.CN) Trung Quốc đã trở thành bá quyền khu vực và thiết lập được quan hệ tương quan quyền lực với các nước láng giềng, được gọi là quan hệ Thiên tử-Chư hầu (hay còn gọi là Phiên giậu). Khi cảm thấy quyền lực bị suy giảm đe dọa đến an ninh và địa vị bá quyền, Trung Quốc, với cách tiếp cận nguồn lực là quyền lực, thường tiến hành các cuộc chiến tranh để chinh phạt hoặc thôn tính nhằm mục tiêu tăng cường quyền lực hoặc tăng cường nguồn lực sản sinh quyền lực (Nguyễn Ngọc Anh, 2017). Với cách tiếp cận này, nếu Trung Quốc muốn đảm bảo an ninh quốc gia ở mức tối đa thì chỉ còn cách là thay thế Mỹ trở thành bá quyền thế giới.

Theo Chủ nghĩa Hiện thực cấu trúc, trong quá trình trỗi dậy các cường quốc mới thường không chấp nhận nguyên trạng do cường quốc cũ tạo ra mà thường tìm cách gia tăng quyền lực nhằm thiết lập một trạng thái cân bằng quyền lực mới ở đó mình là bá quyền (John J. Mearsheimer, 2013). Các biện pháp tăng cường quyền lực thường thấy nhất là mở rộng biên giới lãnh thổ, thách thức địa vị của cường quốc bá quyền hiện trạng, áp đặt ý chí của mình lên các nước khác, tìm cách thay đổi trật tự quốc tế hiện tại theo ý mình. Trung Quốc đang hành xử không khác gì các cường quốc trỗi dậy đã làm trong lịch sử (Mohan Malik, 2014). Câu hỏi đặt ra là Trung Quốc muốn gì trong hệ thống quốc tế? Một câu hỏi nhưng đã có hơn một câu trả lời. Nhiều nghiên cứu về sự trỗi dậy gắn với tham vọng của Trung Quốc cho rằng Trung Quốc muốn trở thành siêu cường số một thay thế Mỹ lãnh đạo thế giới, tức bá quyền thế giới. Các nghiên cứu này cho rằng tham vọng bá quyền thế giới của Trung Quốc được thể hiện trong hàm ý của "Giấc mơ Trung Hoa" và được hiện thực hóa bằng Sáng kiến Một vành đai-Một con đuờng kết nối toàn cầu, $N g a ̂ n$ hàng $A I I B$ và chính sách ngoại giao nước lớn... và cụ thể hơn là phát biểu của Tập Cận Bình: "Nhân loại ngày nay cần nước nhân nghĩa như Trung Quốc dẫn dắt trật tự mới... toàn cầu, ngày nay cần quốc gia có chí hướng như Trung Quốc dẫn dắt cùng nhau giữ gìn an ninh" (Cao Kun, 2017). Thậm chí theo học giả Yun Sun (2015) thì ở Trung Quốc hiện nay người ta đang tập trung thảo luận làm thế nào quản lý quá trình chuyển giao quyền lực từ Mỹ sang Trung Quốc một cách hòa bình và hạn chế mức thấp nhất sự xáo trộn. Tuy nhiên, cũng có nhà nghiên cứu cho rằng Trung Quốc chỉ muốn trở thành bá quyền bờ Tây Thái Bình Dương (Daniel R. Russel, 2016). Trái ngược với các nhận định trên, Trung Quốc cho rằng họ không có gene bá quyền (Patrick Cronin, 2014). Trong lịch sử, Trung Quốc chưa từng một lần trở thành bá quyền thế giới, tuy nhiên lại có thời gian dài tới nghìn năm là bá quyền khu vực. Tham vọng thực sự của Trung Quốc hiện nay là gì có lẽ vẫn cần thêm thời gian để kiểm chứng. Tuy nhiên, có một điều chắc chắn là sự gia tăng quyền lực của Trung Quốc đã tác động đến toàn hệ thống quốc tế và gặp phải trở lực đến từ các chủ thể trong hệ thống này. 


\section{Trở lực từ thể chế, định chế quốc tế}

Hệ thống quốc tế cung cấp môi trường cho các chủ thể trong hệ thống vận hành và phát triển theo quỹ đạo chung. Trong hệ thống quốc tế, mối quan hệ giữa các chủ thể được vận hành dựa trên các luật lệ, quy tắc và thỏa thuận và bên cạnh nhà nước còn có các chủ thể phi nhà nước (Nonstate Actor) như tổ chức quốc tế, công ty xuyên quốc gia, từ đó tạo nên sự đan xen lợi ích giữa nhiều chủ thể khác nhau khiến cho các chủ thể không thể chỉ làm theo ý mình hoặc chỉ nghĩ đến xung đột mà phải điều chỉnh bản thân cho phù hợp hoặc phải hợp tác với nhau (Hoàng Khắc Nam, 2013). Do vậy, vai trò của các thể chế, định chế toàn cầu (Liên Hợp Quốc, Tổ chức Thương mại Thế giới, Quỹ Tiền tệ thế giới...), hay khu vực (Liên minh Châu Âu, Hiệp hội các nước Đông Nam Á...) được tăng cường để bảo đảm ổn định và thúc đẩy sự tương tác giữa các chủ thể. "Các nhà lý thuyết hệ thống cho rằng hệ thống quốc tế có tác động quan trọng lên các nước; môi trường quốc tế ràng buộc và quy định các nước một cách mạnh mẽ" (Helen V. Milner, 2009). Như vậy hệ thống quốc tế tuy theo quan điểm của Chủ nghĩa Hiện thực là vô chính phủ nhưng theo quan điểm của Chủ nghĩa Tự do thì lại không vô tổ chức, ví dụ: năm 2000 Tổ chức Thương mại Thế giới (WTO) buộc siêu cường số 1 thế giới là Mỹ phải hạ thuế đối với mặt hàng thép của Ân Độ; Nghị quyết 1701 năm 2006 của Hội đồng Bảo an Liên Hợp Quốc đã ngăn chặn thành công xung đột Liban-Israel... Những động thái nhằm gia tăng quyền lực của Trung Quốc như tăng cường yêu sách chủ quyền lãnh thổ, thách thức trật tự thế giới hiện tại và áp đặt ý chí của họ lên các nước khác sẽ làm thay đổi cấu trúc quyền lực, trật tự và sự ổn định sẵn có của hệ thống quốc tế do bá quyền Hoa Kỳ chủ đạo thiết kế, duy trì và dẫn dắt gần một thế kỷ qua vì vậy sẽ vấp phải những phản ứng mang tính hệ thống từ các thể chế và định chế trong hệ thống đó.
Những phản ứng mang tính hệ thống là rất nghiêm trọng vì nó có thể khiến địa vị và uy tín của một chủ thể quốc gia bị ảnh hưởng nặng nề trong hệ thống quốc tế. Một ví dụ điển hình là yêu sách của Trung Quốc đối với khoảng 80\% diện tích Biển Đông. Yêu sách này là không phù hợp với Công ước Liên Hợp Quốc về Luật biển (UNCLOS) năm 1982, Tòa Trọng tài Thường trực (PCA) cũng đã bác bỏ yêu sách này. Nếu Trung Quốc phớt lờ và có hành động hiện thực hóa yêu sách của họ thì luật lệ và quy tắc quốc tế sẽ bị phá vỡ, niềm tin của các chủ thể vào các luật lệ, quy tắc, thể chế, định chế quốc tế sẽ bị suy giảm nghiêm trọng... thậm chí có thể khiến trật tự thế giới trở nên hỗn loạn. Điều đó buộc các thể chế, định chế quốc tế phải hành động. Vì vậy, ngay khi Trung Quốc tuyên bố phủ định phán quyết của Tòa PCA thì Liên Hợp Quốc, Liên minh Châu Âu, Hiệp ước Bắc Đại Tây Dương (NATO), Hiệp hội các nước Đông Nam Á (ASEAN)... đều đã lên tiếng yêu cầu Trung Quốc tôn trọng luật pháp quốc tế. Các nhà nghiên cứu cho rằng uy tín của Trung Quốc trong hệ thống quốc tế bị ảnh hưởng nặng nề bởi thái độ hành xử của Trung Quốc sau khi Tòa PCA ra phán quyết về Biển Đông vào tháng 7/2016 (Pinak Chakravarty, 2016).

\section{Trở lực từ một số quốc gia}

Hệ thống quốc tế là hệ thống phụ thuộc lẫn nhau, các chủ thể trong hệ thống vừa có thể bị ảnh hưởng vừa có thể bị tổn thương bởi hành động của các chủ thể khác (Robert Keohane, Joseph Nye, 2001), ví dụ hành động Trung Quốc tăng cường quân sự hóa ở Biển Đông đe dọa chủ quyền lãnh thổ, tự do và an ninh hàng hải đối với một số quốc gia khác; Triều Tiên thử tên lửa hạt nhân ảnh hưởng đến an ninh của các nước khác; thông tin thị trường lao động Hoa Kỳ khởi sắc đã làm tăng điểm thị trường chứng khoán toàn cầu...

Theo Mohan Malik (2014), Trung Quốc đang hành xử không khác gì các cường quốc 
trỗi dậy đã làm trong lịch sử: thiết lập mốc giới mới, vẽ ra các biên giới mới trên đất liền, bầu trời, đại dương quanh khu vực ngoại vi, cố gắng mở rộng biên giới trên bộ và trên biển, hình thành và sửa đổi các thể chế, đồng thời ép các bên khác đi theo quỹ đạo của mình. Những động thái này của Trung Quốc đã và đang đe dọa an ninh và lợi ích quốc gia của nhiều nước khác, gây nên nỗi lo sợ cho các nước láng giềng, nhất là những nước láng giềng có khoảng cách chênh lệch lớn so với Trung Quốc - những quốc gia bị ám ảnh bởi ký ức về "hội chứng Vương quốc Trung Nguyên" hoặc hệ thống các nước Chư hầu. Đứng trước mối đe dọa từ Trung Quốc, các nước này buộc phải có động thái phòng ngừa và ngăn chặn, từ đó hình thành trở lực đối với sự gia tăng quyền lực của Trung Quốc.

\section{Sự chống đối tù các nuơơ láng giềng}

Sự lo ngại của các nước láng giềng đối với sự gia tăng quyền lực của Trung Quốc là do hai nguyên nhân một là thua thiệt khi tranh chấp lãnh thổ với Trung Quốc và hai là bị Trung Quốc áp đặt dẫn đến lệ thuộc vào Trung Quốc và cả hai đều có nguyên nhân lịch sử và hiện tại.

Trong tranh chấp lãnh thổ, các học giả như Thomas Wright (2015) hay Jennifer Lind (2017) và nhiều học giả khác đều cho rằng Trung Quốc là quốc gia theo chủ nghĩa xét lại. Tuy nhiên nếu xét về bản chất thì đây là hệ quả của việc coi nguồn lực là quyền lực (Hoàng Khắc Nam, 2011). Trung Quốc có tranh chấp lãnh thổ với hầu hết các nước láng giềng. Bước sang thế kỷ 21, Trung Quốc đã thể hiện thái độ cứng rắn và quyết đoán hơn, thậm chí đe dọa sử dụng vũ lực. Hậu quả là căng thẳng đã gia tăng trong tranh chấp lãnh thổ giữa Trung Quốc với Nhật Bản, Ấn Độ, Hàn Quốc và đặt biệt là trên Biển Đông khi Trung Quốc muốn "ngăn chặn quân đội Mỹ tự do hành động và dần dần bóp nghẹt, xua đuổi Việt Nam, Philippines và tất cả các nước khác khỏi Biển Đông” (Peter Hartcher, 2016).
Trung Quốc thường sử dụng công cụ kinh tế để gây áp lực và áp đặt ý chí lên các nước láng giềng, chẳng hạn như khiến ASEAN không thể ra được tuyên bố chung vào năm 2012 và gặp khó trong vấn đề ra tuyên bố chung vào năm 2016 (2). Sáng kiến Một vành đai-Một con đường và Hiệp định Đối tác kinh tế toàn diện khu vưc RCEP được xem là hai công cụ chiến lược để Trung Quốc hiện thực hóa mục tiêu của mình. Đây thực chất là cách thức Trung Quốc thực thi và gia tăng quyền lực nhằm đảm bảo an ninh và hiện thực hóa lợi ích quốc gia của họ. Đứng trước tình thế này, các nước láng giềng sẽ có các động thái hoặc công khai, hoặc âm thầm chống lại sự lớn mạnh của quyền lực Trung Quốc. Các động thái này chủ yếu bao gồm:

- Lưa chọn chính sách ngả về Hoa Kỳ để cân bằng quyền lục với Trung Quốc. Nhiều nước láng giềng sẽ ủng hộ, tham gia vào các hoạt động có mục tiêu kiềm chế Trung Quốc của Hoa Kỳ. Chẳng hạn như Hàn Quốc cho phép Hoa Kỳ triển khai hệ thống THAAD và duy trì tập trận chung với Hoa Kỳ dù vấp phải phản ứng dữ dội từ Trung Quốc; Ân Độ đã có động thái xích lại gần Hoa Kỳ; Singapore ủng hộ Hoa Kỳ duy trì sự hiện diện tại Châu Á; Myanmar quyết định bình thường hóa quan hệ với Hoa Kỳ sau hơn 2 thập kỷ gián đoạn; "Malaysia đã tham gia vào chiến lược 'xoay trục' Châu Á-Thái Bình Dương của Washington” (Pamela Sodhy, 2015); Việt Nam "hoan nghênh Hoa Kỳ tiếp tục tham gia, đóng góp tích cực vào việc xây dựng các cấu trúc an ninh, kinh tế khu vực" (Báo Quân đội Nhân dân, 2017)... Động thái này của các nước láng giềng đã trực tiếp gia tăng sức nặng cả về cơ sở pháp lý và sức mạnh thực tiễn cho Hoa Kỳ trong cán cân quyền lực Hoa Kỳ-Trung Quốc và gián tiếp gia tăng sức nặng cho mình trong so sánh quyền lực với Trung Quốc.

\footnotetext{
2 Tham khảo tại website: http://tuoitre.vn/tin/thegioi/20160725/vap-phan-doi-cua-campuchia-aseankhong-ra-duoc-tuyen-bo-chung/1142974.html
} 
- Gia tăng liên minh khu vục để cân bằng quyền lực với Trung Quốc. Đây là biện pháp thường dùng để cân bằng quyền lực khi một vài nước trong một phạm vi địa lý có liên quan cùng phải đối mặt với sự đe dọa từ sự gia tăng quyền lực của một nước nào đó. Đứng trước áp lực do sự gia tăng quyền lực của Trung Quốc, "Châu Á đã hình thành các liên minh mới để ứng phó với Trung Quốc" (Greg Torode, Raju Gopalakrishman, 2017), các nước như Nhật Bản, Ân Độ, Australia... là những nhân tố quan trọng trong các liên minh này.

- Trục tiếp ngăn chặn quyền lục Trung Quốc. Các nước láng giềng dù không muốn đương đầu trực diện với Trung Quốc, nhưng trong những tình huống nhất định họ buộc phải lựa chọn để bảo vệ an ninh và lợi ích quốc gia. Trực tiếp ngăn chặn có thể gồm: (a) bản thân có hành động tấn công trực diện vào tham vọng của Trung Quốc như Singapore kêu gọi tôn trọng phán quyết của Tòa Trọng tài quốc tế về Biển Đông, Indonesia cho nổ các tàu cá nước ngoài đánh cá trên vùng biển đặc quyền kinh tế của mình nhằm ngăn chặn tham vọng trên Biển Đông của Trung Quốc, Myanmar quyết định hủy bỏ dự án đường sắt trị giá 20 tỉ USD mở đường cho Trung Quốc tiến ra Ân Độ Dương qua lãnh thổ của Myanmar; (b) sử dụng công cụ pháp lý để ngăn chặn hành động gia tăng quyền lực của Trung Quốc. Phán quyết của các thể chế quốc tế như Tòa Trọng tài quốc tế, Tổ chức Thương mại quốc tế, Liên Hợp Quốc... đều có sức nặng về mặt pháp lý hoặc đạo đức. Nếu các nước láng giềng thấy cần thiết thì có thể thông qua các thể chế quốc tế này để giải quyết tranh chấp với Trung Quốc, một ví dụ điển hình là Philippines đã kiện Trung Quốc lên Tòa Trọng tài quốc tế. Tuy Trung Quốc tuyên bố phớt lờ, nhưng hậu quả của nó lại khiến uy tín quốc tế của Trung Quốc bị suy giảm nghiêm trọng và quan trọng hơn nó tạo cơ sở pháp lý cho các nước hoặc tổ chức trên toàn cầu tham gia hoặc can thiệp vào. Đối đầu trực tiếp tuy khiến Trung Quốc phải cân nhắc kỹ vì hậu quả của nó, nhưng rủi ro là rất lớn vì nó có thể châm ngòi cho căng thẳng và leo thang thành xung đột.

- Hợp tác để kiềm chế. Đây được xem là biện pháp tuy có vẻ không quyết liệt và đòi hỏi nhiều trí tuệ cũng như thời gian, nhưng nó không chỉ mang lại hiệu quả cao mà còn tránh được nhiều rủi ro. Theo lý thuyết của Chủ nghĩa Tự do thể chế (Karen A. Mingst, Ivan M. Arreguin-Toft, 2013) thì tuy hệ thống quốc tế là vô chính phủ, nghĩa là không có một siêu nhà nước đứng bên trên điều phối, tổ chức và chế tài quan hệ giữa các nước trong toàn hệ thống quốc tế, nhưng không vì thế mà các nước có thể tùy ý làm theo ý muốn và chỉ chọn trò chơi tổng bằng không vì như thế họ sẽ phải trả cái giá cao hơn, thậm chí trong nhiều trường hợp cái giá phải trả là quá cao. Thay vào đó, các nước có xu hướng hợp tác với nhau trong khuôn khổ những thể chế, định chế quốc tế để giảm thiểu sự trả giá, đồng thời tăng lượng thông tin và giảm tính bất định (Robert O. Keohane, 1984). Các nước láng giềng của Trung Quốc thông qua việc thiết lập các thể chế, định chế và cơ chế hợp tác có sự tham gia của Trung Quốc để kiềm chế sự gia tăng quyền lực của Trung Quốc vì khi đã tham gia vào thì "không phải sức mạnh quốc gia dẫn đến sự tuân thủ mà là một cơ chế phức tạp buộc các nước coi trọng nghĩa vụ của họ được quy định trong các hiệp định mà họ đã ký" (Helen V. Milner, 2009). Diễn đàn khu vục ASEAN (ARF), Hội nghị thương đỉnh Đông Á (EAS), Tuyên bố về ưng xủ của các bên ở Biển Đông (DOC) và tiến tới là $B \hat{Q}$ quy tắc ứng xủ̉ ở Biển Đông (COC), Đối thoại Shangri-La (Shangri-La Dialogue)... đều là những công cụ kiềm chế hữu hiệu đối với quyền lực của Trung Quốc. Ngay cả Sáng kiến Một vành đai - Một con đương (OBOR) do Trung Quốc khởi xướng nhưng với sự tham gia của hầu hết các nước láng giềng cũng khiến Trung Quốc không dễ áp đặt ý chí của mình, thậm chí có trường 
hợp Trung Quốc còn phải nhượng bộ để tránh đổ vỡ.

- Sư dụng đòn bẩy hệ thống quốc tế. Đây cũng được xem là một biện pháp hữu hiệu giúp ngăn chặn sự gia tăng quyền lực của Trung Quốc. Các nước láng giềng Trung Quốc có thể sử dụng sức mạnh từ sự đa dạng của chủ thể (các quốc gia, công ty xuyên quốc gia, tổ chức quốc tế...) trong hệ thống quốc tế và sự phụ thuộc giữa các chủ thể này để gây sức ép ngăn chặn Trung Quốc. Chẳng hạn như Biển Đông chiếm $1 / 3$ lưu lượng thương mại thế giới nên các nước có tranh chấp Biển Đông với Trung Quốc có thể dựa vào các chủ thể có lợi ích liên quan trên Biển Đông như Nhật Bản, Hoa Kỳ, Liên minh châu Âu và các tổ chức có chức năng liên quan như Tổ chức Minh bạch quốc tế (TI), Tổ chức Sáng kiến minh bạch hàng hải Châu Á (AMTI), Tổ chức Theo dõi nhân quyền (HRW) để cùng tham gia ngăn chặn Trung Quốc.

\section{Sư cạnh tranh tù các nước lớn láng giềng}

Theo sử gia Graham Allison (2017), Trung Quốc đang đi con đường mà Mỹ đã từng đi ở đầu thế kỷ 20 để trở thành siêu cường. Khi đó, Mỹ đã xung đột với Tây Ban Nha (ở Philippines), Đức (ở Venezuela) và Anh (ở Alaska) để gia tăng quyền lực và áp đặt ý chí của mình ở Châu Mỹ Latin. Việc Trung Quốc cứng rắn với láng giềng ở Biển Đông và Hoa Đông tương tự như Mỹ đã làm ở Caribbean thời kỳ đó. Điều đó đe dọa an ninh và địa vị của các nước lớn, nhất là các nước lớn láng giềng như Nga, Ân Độ và Nhật Bản. Đã có những cạnh tranh công khai hoặc âm thầm giữa ba quốc gia này với Trung Quốc.

Nga, Ân Độ và Nhật Bản có điểm chung là đều tranh chấp lãnh thổ với Trung Quốc (Trung Quốc cho rằng, trong thế kỷ $19, \mathrm{Nga}$ Hoàng đã chiếm hơn 1,9 triệu km² lãnh thổ của Trung Quốc). Trong giải quyết tranh chấp lãnh thổ, ba nước này tuy có thể lựa chọn các biện pháp như các nước láng giềng nhỏ, nhưng vì là nước lớn nên thường thiên về lựa chọn biện pháp đối đầu trực tiếp, điển hình là căng thẳng leo thang tại biên giới giữa Trung Quốc và Ấn Độ và những va chạm giữa Nhật Bản và Trung Quốc trên biển Hoa Đông.

Nga, Ân Độ và Nhật Bản đã có ảnh hưởng và địa vị quốc tế và khu vực nhất định, đều có sân sau là các nước nhỏ hoặc là láng giềng hoặc gần với Trung Quốc. Vì vậy cuộc cạnh tranh giữa ba nước đó với Trung Quốc đã và đang diễn ra trên phạm vi toàn cầu, trong đó quyết liệt nhất là ở sân sau của các nước.

Cạnh tranh quyền lực Trung - Nhật diễn ra trên phạm vi toàn cầu phải kể đến là Nhật muốn trở thành ủy viên thường trực Hội đồng Bảo an Liên Hợp Quốc, nhưng Trung Quốc lại phản đối quyết liệt.

Cuộc cạnh tranh Trung - Nhật tiếp tục diễn ra tại Châu Phi với cuộc chạy đua về đầu tư nhằm giành lấy cảm tình của các nước ở châu lục này. Nhật Bản không ngừng nâng cấp Lực lượng Phòng vệ, năm 2015, Quốc hội Nhật Bản đã thông qua dự luật cho phép Lực lượng Phòng vệ tham chiến ở nước ngoài nhằm cạnh tranh ảnh hưởng về quân sự với Trung Quốc. Nhưng quyết liệt nhất là cuộc cạnh tranh Trung-Nhật tại khu vực Đông Nam Á. Nhật Bản không chỉ đầu tư, viện trợ về kinh tế, mà còn trợ giúp khí tài, ủng hộ và vận động các nước khác tham gia trợ giúp các nước ở Đông Nam Á có tranh chấp lãnh thổ với Trung Quốc. Trên mặt trận tâm lý và công luận, Nhật Bản đã phác họa ra khắp thế giới chân dung một Trung Quốc đang trỗi dậy là mối đe dọa với hòa bình và trật tự thế giới được gọi là 'Mối đe dọa Trung Quốc' ${ }^{\text {'(3) từ đó }}$ dẫn đến tâm lý e ngại và cảnh giác đối với sự trỗi dậy của Trung Quốc.

3 Rajaram Panda (2014). Japan's Defense White Paper 2014 and Coping with the China 'Threat'. Lisboa (PORTUGAL): Portuguese Institute of International Relations and Security (IPRIS) và Foxnews (2015). Japan defense report stresses China's threat as Tokyo pushes to give its military greater role, http://www. foxnews.com/world/2015-07/20/japan-defense-reportstresses-china-threat-as-tokyo-pushes-to-give-itsmilitary.html 
Cạnh tranh quyền lục Trung - Ân cũng không kém phần quyết liệt ở cấp khu vực. Ân Độ đã nâng cấp Chính sách hướng Đông (Look East Policy) thành Hành động hướng Đông (Act East Policy) nhằm ngăn chặn yêu sách của Trung Quốc trên Biển Đông, với mục đích bảo vệ lợi ích quốc gia của mình trên Biển Đông và xa hơn là ngăn chặn ý đồ tiến ra Ấn Độ Dương của Trung Quốc(4).

Ân Độ từ chối tham gia Sáng kiến Một vành đại - Một con đường do Trung Quốc khởi xướng và xây dựng Con đường tơ lua mới của mình để tranh giành sân sau với Trung Quốc (Archana Chaudhary, Dhwani Pandya, 2017) khiến Trung Quốc gặp không ít khó khăn trong việc gia tăng quyền lực tại khu vực Châu Á.

Tập Cận Bình cho rằng quan hệ Nga Trung đang ở thời điểm tốt nhất trong lịch sử (Xinhua, 2017), Tổng thống Nga nói quan hệ Nga - Trung duy trì ở mức cao chưa từng thấy (Alexander Druzhinin, 2017), nhưng cạnh tranh quyền lực Nga - Trung vẫn âm thầm diễn ra vì "Nga nhận thức rằng, Trung Quốc là mối đe dọa trong dài hạn đặc biệt đối với an ninh và sự toàn vẹn lãnh thổ của Nga ở các tỉnh Viễn Đông ven bờ Thái Bình Dương mà Trung Quốc vẫn nhòm ngó và đã cho hàng ngàn người Trung Quốc di cư sang bất hợp pháp" (Subhash Kapila, 2015).

Trong khi Nga bị Phương Tây áp đặt lệnh cấm vận, Trung Quốc đã gia tăng ảnh hưởng tại các nước vốn là sân sau của Nga. Vì vậy, Nga buộc phải điều chỉnh chính sách Xoay trục sang Châu Á nhằm xích lại gần hơn với Nhật Bản, Ân Độ và các nước Đông Nam Á để ngăn ngừa Trung Quốc. Trở lực lớn nhất đối với Trung Quốc đến từ Nga hiện nay là

\footnotetext{
${ }^{4}$ Tham khảo bài phát biểu của Thủ tương Ấn Độ Narendra Modi tại Hội nghị cấp cao Đông Á (EAS) tổ chức ở Myanmar năm 2014. Bài viết đăng tải trên website của Bộ Ngoại giao Ấn Độ: http://mea.gov.in/ Speeches-Statements.htm?dtl/24238/Prime+Ministers+ remarks + at + the +9 th + East + Asia + Summit + Nay + Pyi + Ta w+Myanma
}

việc Nga gia tăng bán vũ khí cho các đối thủ của Trung Quốc ở Châu Á đã khiến Trung Quốc bị suy yếu (Emanuele Scimia, 2017).

\section{Sụ kiềm chế tù bá quyền hiện trạng Hoa Kỳ}

Theo thuyết Hiện thực cấu trúc, cường quốc mới nổi sẽ không dễ dàng chấp nhận hiện trạng mà có xu hướng phá vỡ trật tự hiện có để trở thành chủ thể chi phối trật tự mới, tức bá quyền, trong khi đó cường quốc hiện trạng sẽ tìm cách ngăn cản nước mới nổi trở thành bá quyền. Đây là lý do "Mỹ từ lâu đã tìm cách ngăn cản bất cứ cường quốc nào nắm bá quyền ở châu Á, trong khi Trung Quốc lại muốn giữ các đối thủ tiềm năng ở vị trí cách xa bờ biển của họ" (The Economist, 2017). Chính sách Xoay trục Châu Á kiềm chế Trung Quốc của Mỹ chính thức bắt đầu năm 2011 khi Ngoại trưởng Hoa Kỳ lúc đó là Hillary Clinton tuyên bố là "sự trở lại khu vực phù hợp với nỗ lực toàn cầu nhằm bảo vệ và duy trì vai trò lãnh đạo toàn cầu của Hoa Kỳ" (Hillary Clinton, 2011) từ đó quan hệ Hoa Kỳ - Trung Quốc trở nên căng thẳng, thậm chí có ý kiến cho rằng chiến tranh giữa hai quốc gia sẽ là tất yếu (Graham Allison, 2017).

Năm 2017, Tổng thống Donald Trump tuyên bố thay đổi Chính sách "Tái cân bằng" châu Á - Thái Bình Dương của chính quyền Obama, nhưng trở lực lớn nhất đối với Trung Quốc đến từ Hoa Kỳ là từ lâu, Hoa Kỳ đã thiết lập vòng vây 3 tầng trên biển đối với Trung Quốc bao gồm các liên minh quân sự và hệ thống căn cứ quân sự để ngăn chặn Trung Quốc trở thành cường quốc biển và xây dựng khả năng tấn công vào tử huyệt của Trung Quốc trên biển là eo biển Malacca (Alexey Pilko, 2012). 


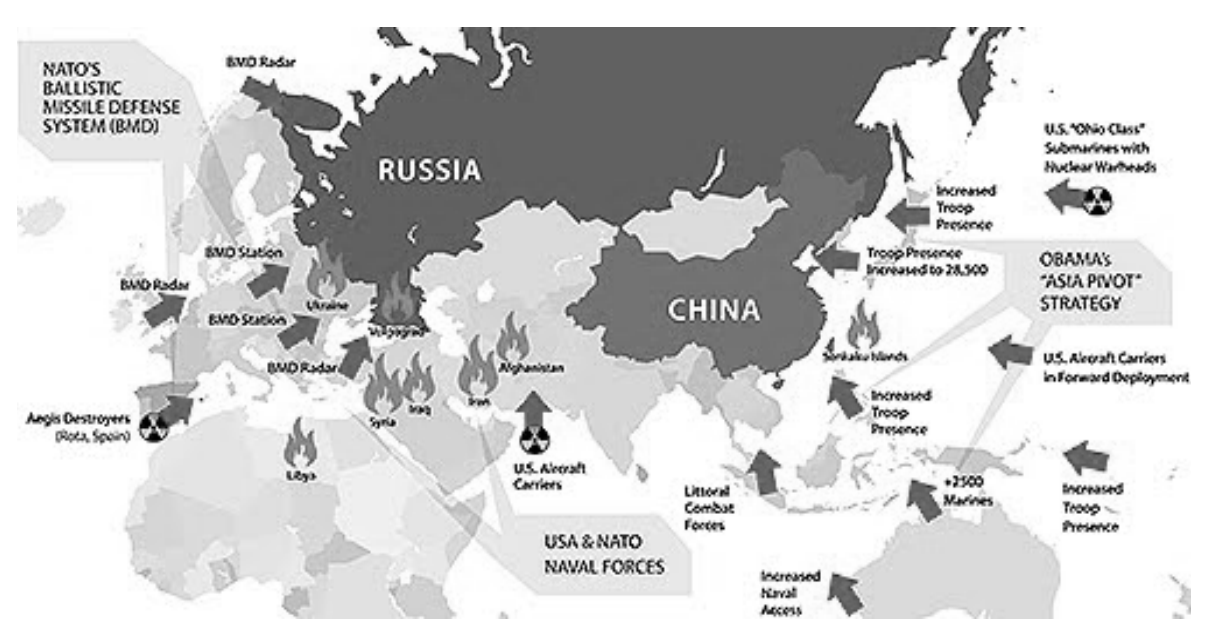

Vòng vây ba tầng trên biển của Mỹ đối với Trung Quốc

(Nguồn: http://www.the5thestate.asia)

Đồng thời, Hoa Kỳ còn có những động thái kiềm chế sự gia tăng quyền lực của Trung Quốc như ủng hộ bao gồm cả kinh tế và quân sự đối với các nước có tranh chấp lãnh thổ với Trung Quốc như Việt Nam, Ân Độ, Philippines..., can dự trực tiếp vào tranh chấp Biển Đông để bảo vệ lợi ích chiến lược của mình, tích cực tham gia và thúc đẩy các diễn đàn khu vực như Đối thoại Shangri-La (Shangri-La Dialogue), ASEAN+... để ngăn chặn hành vi gia tăng quyền lực và áp đặt ý chí của Trung Quốc.

Ngoài ra, theo Trung Quốc, Hoa Kỳ đã, đang và sẽ tích cực phối hợp với các nước khác thực thi các chính sách nhằm bảo vệ Đài Loan, ngầm ủng hộ các lực lượng đấu tranh đòi "ly khai" ở Hồng Kông, Tây Tạng, Tân Cương...làm tan rã Trung Quốc; tiến hành “cách mạng màu sắc", các cuộc "chiến tranh thương mại”... đối với Trung Quốc, làm suy yếu ngay trong lòng đất nước Trung Quốc, khiến cho Trung Quốc không dễ dàng thực hiện mục tiêu trở thành bá quyền.

\section{Trở lực và tương lai bá quyền của Trung Quốc}

Trung Quốc có trở thành bá quyền hay không là một câu hỏi đang được giới nghiên cứu quốc tế trên toàn cầu quan tâm và đi tìm lời giải đáp. Hiện nay đã có hai nhận định trái ngược nhau: trong khi một số học giả mà tiêu biểu là Martin Jacques, Kishore Mahbubani cho rằng Trung Quốc sẽ trở thành bá quyền trong tương lai, thì các học giả khác mà tiêu biểu là Will Hutton, David Shambaugh lại cho rằng Trung Quốc sẽ không thể trở thành bá quyền. Có rất nhiều trở lực đến từ những chủ thể khác trong hệ thống quốc tế, để trở thành bá quyền, Trung Quốc trước tiên không thể không vượt qua những trở lực đã phân tích ở trên.

Để vượt qua những trở lực này, đầu tiên Trung Quốc cần phải có một quyền lực vượt trội và có sự kết hợp nhuần nhuyễn giữa quyền lực cứng và quyền lực mềm, hay còn gọi là Quyền lục thông minh.

Chúng ta hãy xem xét ba thành tố trọng yếu cấu thành quyền lực cứng của Trung Quốc:

Quân sự, Trung Quốc cần một đội quân hùng mạnh đủ để áp chế những thách thức và phản kháng cũng như có tác dụng răn đe đối với các chủ thể như đã nói ở trên, đồng thời đảm bảo cho một trật tự do mình thiết lập hoặc dẫn dắt được vận hành ổn định. Tuy nhiên theo đánh giá của Globalfirepower (2017), Trung Quốc vẫn còn có khoảng cách với láng giềng phương Bắc là $\mathrm{Nga}$ và còn có khoảng cách khá xa so với Hoa Kỳ. Trung Quốc lại không có các liên minh quân sự như Hoa Kỳ, vì vậy, Trung Quốc sẽ không thể sử dụng giải 
pháp quân sự để giải quyết các trở lực từ Hoa Kỳ, Nga cũng như đồng minh của Hoa Kỳ là Nhật Bản, Hàn Quốc hay Philippines.

Kinh tế, Trung Quốc cần một nền kinh tế đủ mạnh để chi trả cho các chi phí, đảm bảo việc thực thi hiệu quả việc thưởng phạt đối với các chủ thể nói trên, đồng thời đảm nhiệm được vai trò là đầu tàu kinh tế của một bá quyền. Trung Quốc hiện là nền kinh tế lớn thứ 2 thế giới nhưng thu nhập bình quân đầu người chỉ ở mức trung bình. Hiện nay, Trung Quốc đang phải vật lộn với sự trì trệ tăng trưởng và nợ công tăng cao trên con đường suy thoái (Ruchir Sharma, 2016). Trung Quốc thường dùng các biện pháp kinh tế để áp đặt ý chí chẳng hạn như năm 2012, hạn chế xuất khẩu đất hiếm sang Nhật vì tranh chấp ở Biển Hoa Đông, năm 2014, dựng rào cản với nông sản của Philippines vì tranh chấp Biển Đông, năm 2017, cấm các tour du lịch đến Hàn Quốc để phản đối lá chắn tên lửa THAAD... Viện trợ và đầu tư là những biện pháp thường thấy khi Trung Quốc muốn thuyết phục một nước nào đó nhưng do hậu quả nhãn tiền của nó nên không ít nước đã cảnh giác thậm chí là khước từ. Là nước xuất khẩu lớn nhất thế giới và là thành viên của các tổ chức và hiệp định thương mại, Trung Quốc không thể và cũng không đủ sức sử dụng các biện pháp như cấm vận kinh tế để khiến cho các chủ thể trên phải thỏa hiệp với Trung Quốc.

Khoa học - công nghệ, Trung Quốc cần có một nền khoa học - công nghệ phát triển trước tiên là để thúc đẩy đất nước và đặc biệt là hai thành tố của quyền lực cứng là quân sự và kinh tế phát triển và sau đó là đảm đương vai trò dẫn dắt trào lưu khoa học - công nghệ bằng những sản phảm và thương hiệu đỉnh cao, tiêu biểu. Trung Quốc hiện đã có những tiến bộ vượt bậc về khoa học - công nghệ, tuy nhiên "khả năng của người Trung Quốc thường được định hướng 'hạ nguồn': hấp thụ những công nghệ được nhập khẩu, đơn giản hóa khâu sản xuất, và sửa những thiết kế tiên tiến thành những sản phẩm bình thường hơn với giá rẻ hơn" vì vậy trong những sản phẩm công nghệ tiêu biểu thế giới, Trung Quốc không có sản phẩm nào (Pankaj Ghemawat \& Thomas Hout, 2016).

\section{Quyền lực mềm của Trung Quốc}

Đã có những tranh luận về quyền lực mềm của Trung Quốc, nhưng đa phần các nghiên cứu đều cho rằng quyền lực mềm là hạn chế và lực cản lớn nhất đối với Trung Quốc trên con đường trỗi dậy. Nguyên nhân là do Trung Quốc nhận thức sai về quyền lực mềm (Yinwei, 2008) và để cho quyền lực cứng phá hỏng quyền lực mềm (Carrie Gracie, 2015). Theo Joseph Nye (2004), quyền lực mềm phải là sự hấp dẫn, quyến rũ khiến đối phương yêu thích, say mê và tự nguyện làm theo. Cũng theo Joseph Nye (2015), Trung Quốc tuy có những nỗ lực rất lớn để gia tăng quyền lực mềm, nhưng kết quả thu được là rất hạn chế do chính sách của Trung Quốc thường gây ra quan ngại và sợ hãi cho các nước khác.

Giá trị phổ quát là yếu tố cốt lõi của quyền lực mềm và giá trị này phải được chia sẻ mới có thể trở thành quyền lực mềm. Trung Quốc không phải là không có các giá trị phổ quát tuy nhiên lại ít được chia sẻ với các nước khác. Sự lên án của các chủ thể trong hệ thống quốc tế bị Trung Quốc chèn ép như Philippines hay Việt Nam; lời kêu gọi Trung Quốc tôn trọng luật pháp quốc tế từ các chủ thể trong hệ thống quốc như Mỹ, Nhật, EU...; lời nhắc nhở của Ngoại trưởng Nhật Bản là "Trung Quốc cần học cách hành xử như một nước lớn" (Kyodo, 2017) hay lời cảnh báo của Thủ tướng Australia Malcolm Turnbull về sự chèn ép của Trung Quốc đối với các nước Châu Á (The Guardian, 2017); hình ảnh về các công ty Trung Quốc tàn phá môi trường ở Châu Phi; các nước nghèo nhu Sri Lanka; Pakistan, Campuchia, Myanmar... mắc kẹt trong "bẫy nợ ngoại giao Trung Quốc" (Brahma Chellaney, 2017)... là những bằng chứng cho thấy Trung Quốc không chia sẻ giá trị phổ quát. 
Tiếp theo là sự chấp nhận của các chủ thể tạo ra các trở lực này. Để có được sự chấp nhận này thì Trung Quốc cần phải đáp ứng được ít nhất hai điều kiện căn bản; đó là hoàn cảnh, môi trường quốc tế và triển vọng. Môi trường quốc tế hiện tại chưa thuận lợi cho Trung Quốc vì sự nghi ngại của cộng đồng quốc tế đối với sự trỗi dậy của Trung Quốc ngày một tăng cao đã tác động tiêu cực đến tâm lý và hành vi của các chủ thể này. Chưa có bằng chứng cho thấy hoàn cảnh quốc tế hiện nay đòi hỏi hay tạo điều kiện cho Trung Quốc trở thành bá quyền, vì vậy, chưa thể thuyết phục được các chủ thể này rằng về khách quan cần phải có Trung Quốc dẫn dắt. Triển vọng là một trong những nhân tố đặc biệt quan trọng giúp Trung Quốc vượt qua các trở lực này. Hiện tại, Trung Quốc chưa phải là một quốc gia hình mẫu hay nơi hội tụ của những tinh hoa và thành tựu, bên cạnh đó là sự hạn chế của quyền lực mềm, vì vậy, chưa có cơ sở để thuyết phục các chủ thể này rằng một tương lai an toàn, hòa bình và thịnh vượng sẽ được kiến tạo dưới sự dẫn dắt của Trung Quốc.

\section{Kết luận}

Dù các nước luôn phản đối bá quyền nhưng trên thực tế thì đa phần tại mỗi giai đoạn lịch sử nhất định đều xuất hiện một hoặc một vài quốc gia bá quyền trong những phạm vi địa lý khác nhau. Giới nghiên cứu lý thuyết quan hệ quốc tế đã có những nhận định khác nhau về vai trò của bá quyền. Chủ nghĩa Hiện thực cho rằng sự phân bổ quyền lực giữa các quốc gia trong hệ thống là một nhân tố trung tâm cho sự ổn định của nền kinh tế - chính trị thế giới. Quốc gia bá quyền do có quyền lực vượt trội nên có thể thiết lập và áp đặt các luật chơi rồi bắt các quốc gia khác phải tuân thủ vì vậy tránh được tình trạng hỗn loạn. Trong khi đó Chủ nghĩa Tự do lại cho rằng sự ổn định kinh tế chính trị có được là nhờ vào những thể chế, cơ chế và sự hợp tác do các quốc gia cùng nhau xây dựng chứ không phải chỉ dựa vào quyền lực.
Hệ thống quốc tế là sự phụ thuộc vào nhau, vì vậy có lẽ câu hỏi đặt ra hiện nay đối với các quốc gia không phải là có cần thiết phải có bá quyền hay không mà là quốc gia nào là bá quyền và sự bá quyền đó trước tiên có đe dọa đến an ninh và lợi ích quốc gia của mình hay không và sau đó là sẽ kiến tạo nên một trật tự thế giới như thế nào. Hoa Kỳ là bá quyền thế giới gần một thế kỷ nay. Tuy đã từng dùng các biện pháp cưỡng bức để mở rộng lãnh thổ, thiết lập một trật tự thế giới và ép buộc các nước khác đi theo trật tự đó và còn có những hạn chế nhất định, nhưng Hoa Kỳ đã kiến tạo nên một trật tự thế giới giúp cho loài người phát triển đi lên. Học giả Gideon Rachman (2015) cho rằng Hoa Kỳ tin rằng tiến bộ là quy luật tự nhiên, mọi người sinh ra đều bình đẳng; thượng tôn pháp luật; tin tưởng và chia sẻ các giá trị phổ quát trong khi đó, Trung Quốc lại ngược lại.

Một trật tự thế giới do Trung Quốc kiến tạo và dẫn dắt sẽ thế nào chắc chắn phải đến lúc đó mới biết được, nhưng điều chúng ta đã biết được là Trung Quốc đã và đang gặp phải các trở lực và việc vượt qua các trở lực này là không hề dễ dàng.

\section{Tài liệu tham khảo}

\section{Tiếng Việt}

Nguyễn Ngọc Anh (2017). Tranh chấp Biển Đông: Thách thức trong quan hệ ASEAN-Trung Quốc nhìn từ cách tiếp cận của Trung Quốc về quyền lực. Tạp chí Nghiên cứu Nước ngoài, Tập 33, Số 2, 12-22.

Nguyễn Ngọc Anh (2017). Tư tưởng “Trung tâm quyền lực" của Nho giáo và ảnh hưởng của nó đến quan hệ Việt-Trung. Kỷ yếu HTKH quốc gia 2017 Nghiên cúu và giảng dạy ngoại ngũu, ngôn ngũu, quốc tế học tại Việt Nam. Hà Nội ngày 18/4/2017, tr. 59-65.

Hoàng Khắc Nam (2013). Chủ nghĩa Tự do trong quan hệ quốc tế: Những luận điểm chính và sự đóng góp. Khoa họ Xã hội \& Nhân văn, Tập 29, Số 1, 17-26.

Hoàng Khắc Nam (2011). Quyền lực trong quan hệ quốc tế, lịch sư và vấn đề. Hà Nội: Nxb Văn hóa thông tin.

Báo Quân đội Nhân dân (2017). Thủ tuớng Nguyễn Xuân Phúc hội đàm với Tổng thống Donald Trump. Truy cập lúc 15:20 ngày 12/8/2017 tại http://www. qdnd.vn/doi-ngoai/doi-ngoai/thu-tuong-nguyenxuan-phuc-hoi-dam-voi-tong-thong-donaldtrump-508798 


\section{Tiếng Anh}

Alexander Druzhinin (2017). Putin says Russia, China maintain relations at, unprecedentedly high level. Available through <http://tass.com/ politics/943442>, Accessed 13/8/2017 15:15

Alexey Pilko (2012). America's policy of "Containment of china”. Available through $<$ http://www.globalresearch. ca/america-s-policy-of-containment-of-china/30354>, Accessed 13/8/2017 16:15

Archana Chaudhary, Dhwani Pandya (2017). India Builds Highway to Thailand to Counter China's Silk Road. Available through <https://www.bloomberg. com/news/articles/2017-08-08/china-s-silk-road-lendsurgency-to-india-s-regional-ambitions $>, \quad$ Accessed 14/8/2017 15:15

Carrie Gracie (2015). China power audit: The hard and the soft. Available through < http:// www.bbc.com/news/explainers-35100098>, Accessed 23/8/2017 16:15

Emanuele Scimia (2017). Russia's arms sales weaken China in the Indo-Pacific area. Available through <http://www.atimes.com/ russias-arms-sales-weaken-china-indo-pacificarea/>, Accessed 11/8/2017 19:15

Gideon Rachman (2017). Easternization: Asia's Rise and America 's Decline. New York, NY: Other Press.

Gideon Rachman (2015). The ideas that divide China and America. Available through $<\mathrm{https}: / / \mathrm{www}$. ft.com/content/d3a08664-65c2-11e5-a28b50226830d644>, Accessed 25/8/2017 19:15

Globalfirepower (2017). 2017 Military Strength Ranking. Available through < http://www. globalfirepower.com/countries-listing.asp>, Accessed 21/8/2017 11:15

Graham Allison (2017). Destined for War: Can America \& China escape Thucydide's Trap? New York, NY: Houghton Mifflin Harcourt.

Greg Torode, Raju Gopalakrishman (2017). Unsure of U.S., Asia builds new alliances to counter China. Available through $<\mathrm{http} / / /$ ca.reuters. com/article/topNews/idCAKBN18V0LZOCATP?sp=true $>$, Accessed 11/8/2017 14:15

Helen V. Milner (2009). Power, Interdependence, and Nonstate Actors in World Politics: Research Frontiers. Princeton, NJ: Princeton University Press, pp. 3-27.

John J. Mearsheimer (2013). Structural Realism, in Tim Dunne, Milja Kurki, Steve Smith (ed.), International Relations Theories Discipline and Diversity, $3^{\text {th }}$ editon. OX: Oxford University Press, 77-93.

Joseph Nye (2004). Soft Power: The Means to Success in World Politics. New York, NY: PublicAffairs

Joseph Nye (2015). The Limits of Chinese Soft Power. Available through $<$ https://www.project- syndicate.org/commentary/china-civil-societynationalism-soft-power-by-joseph-s--nye-201507?barrier=accessreg $>$, Accessed 31/7/2017 11:15

Karen A Mingst, Ivan M Arreguin - Toft (2014). Essentials of International Relations. New York: W.W. Norton\&Company.

Kjeld Erik Brødsgaard (2017). Critical Readings on the Chinese Communist Party. Leiden (The Netherlands): BRILL.

Kyodo (2017). Kono urges China to learn 'how to behave as a big power'. Available through < https:// www.japantimes.co.jp/news/2017/08/08/national/politicsdiplomacy/kono-urges-china-learn-behave-big power/\#. WaPfwD4jHIU>, Accessed 31/7/2017 11:15

Michael D. Swaire (2010). Perceptions of an Assertive China. China Leadership Monitor, No.32, 1-19.

Mohan Malik (2014). China and Strategic Imbalance. Available through <http:// thediplomat.com/2014/07/china-and-strategicimbalance/>, Accessed 31/7/2017 11:15

Pamela Sodhy (2015). U.S.-Malaysia Relations on the Security Front. NBR analysis brief. Available through <http://www.nbr.org/ publications/analysis/pdf/brief/031315 Sodhy_Malaysia.pdf $>$, Accessed 1/8/2017 9:15

Pankaj Ghemawat \& Thomas Hout (2016). Can China's Companies Conquer the World? Available through <https://www.foreignaffairs. com/articles/united-states/can-chinas-companiesconquer-world $>$, Accessed 8/8/2017 19:15

Patrick Cronin (2014). How to Deal with Chinese Assertiveness: It's Time to Impose Costs. Available through $\quad<\mathrm{http}: / /$ nationalinterest.org/feature/ how-deal-chinese-assertiveness-its-time-imposecosts-11785>, Accessed 21/8/2017 11:15

Peter Hartcher (2016). South China Sea: The fight China will take to the brink of war. Available through <http://www.smh.com.au/comment/ south-china-sea-the-fight-china-will-take-tothe-brink-of-war-20160425-goe3zi.html>, Accessed 1/8/2017 14:15

Pinak Chakravarty (2016). South China Sea verdict: Now China's international reputation at stake. Available through <http://www.orfonline.org/ research/south-china-sea-verdict-now-chinasinternational-reputation-at-stake/>, Accessed 25/8/2017 17:15

Robert O. Keohane, Joseph Nye (2001). Power and Interdependence ( $3^{\text {thed }}$ ). New York, NY: Longman.

Robert O. Keohane (1984). After Hegemony: Cooperation and Discord in the World Political Economy. Princeton, NJ: Princeton University Press. 
Ruchir Sharma (2016). How China Fell Off the Miracle Path. Available through $<\mathrm{https}: / /$ www.nytimes.com/2016/06/05/opinion/ sunday/how-china-fell-off-the-miracle-path. html?_r=0>, Accessed 8/8/2017 14:15

Stephan Ortmann, Mark R. Thompson (2016). „China and The 'Singapore Model'". Journal of Democracy, .27(1), 39-48.

Subhash Kapila (2015). Russia-China Strategic Nexus: How Strategic? Available through $<$ http://www. eurasiareview.com/06102015-russia-chinastrategic-nexus-how-strategic-analysis/>, Accessed 10/8/2017 11:15

The guardian (2017). Malcolm Turnbull warns Asian leaders of 'a coercive China'. Available through $<$ https://www.theguardian.com/ australia-news/2017/jun/03/malcolm-turnbullwarns-asian-leaders-of-a-coercive-china $>$, Accessed 20/8/2017 11:15

Xinhua (2017). Xi says China-Russia relations 'at best time in history'. Available through <http://www.chinadaily.com.cn/ world/2017xivisitgermany/2017-07/03/ content 29977487.htm>, Accessed 14/8/2017
17:15

Yinwei (2008). Public Diplomacy and the Rise of Chinese Soft Power. The Annals of the American Academy of Political and Social Science, 616, 257-273

Yun Sun (2015). China's Preferred World Order: What Does China Want? PacNet, No.62. Honolulu, Hawaii: Pacific Forum CSIS.

Zhizhen Lu (2017). China's Nationalist Foreign Policy in a Globalized Era: Historical Logic, Confident Insecurity, and Domestic Politics. International Affairs Review, Vol. XXV, No.1. Available through $<$ http://iar-gwu.org/content/volume-xxv-no-1winter-2017>, Accessed 14/8/2017 120:15

\section{Tiếng Trung Quốc}

Cao Kun (2017). 习近平 “两个引导”. Available through <http://politics.people.com.cn/n1/2017/0220/ c1001-29094518.html>, Accessed 2/5/2017 23:15

\title{
SOME OBSTACLES OF THE INTERNATIONAL SYSTEM TO CHINA'S DREAM OF HEGEMONY
}

\author{
Nguyen Ngoc Anh \\ Center of Linguistics and International Studies, \\ VNU University of Languages and International Studies, \\ Pham Van Dong, Cau Giay, Hanoi, Vietnam
}

\begin{abstract}
The research firstly analyses some comments on China's ambition of power, and then shows the obstacles of the international system to this ambition such as institutions, neighboring countries and the US. The research posits that it is not easy for China to overcome these because there is still a long way ahead for China to achieve dominating power.
\end{abstract}

Keywords: China, hegemony, international system, power 